\title{
The Comparison and Analysis of Humidity Environment between Floor and Ceiling Radiant Cooling Systems that Combined with Displacement Ventilation
}

\author{
Kai SUN ${ }^{1 a^{*}}$, Chuan-hui ZHOU ${ }^{1}$ \\ ${ }^{1}$ College of Urban Construction, Wuhan University of Science and Technology, Wuhan, China \\ a 1756266062@qq.com
}

Keywords: Radiant Cooling, Displacement Ventilation, Thermal Stratification, Relative Humidity, CFD.

Abstract. At present, the study on the temperature fields of floor radiant cooling system and ceiling radiant cooling system based on displacement ventilation is more, but for the humidity field research of the two systems is insufficient. There is a thermal stratification in the temperature field of both kinds of radiant cooling systems, and the temperature gradient is significantly different in both systems: the indoor temperature field is relatively uniform and the vertical temperature gradient is small in the ceiling radiant systems. While adopting the floor radiant cooling system, the indoor vertical temperature stratification is more obvious. Humidity field has an impact on the dewing problem of radiant cooling air conditioning system and human body comfort, and whether there are the same features of the humidity field in two kinds of systems as the temperature field are also worth exploring. Therefore, starting with anti-condensation control strategies and working conditions of different moisture quantity, the humidity fields which are in the two kinds of systems that radiating surface location is different are studied in this paper. Results show that in the two systems, there are thermal stratification and humidity stratification, and stratification height is consistent. Under the same initial conditions, the anti-condensation effect of floor radiant cooling combined with displacement ventilation is better.

\section{Introduction}

Because of the limitation of comfort, condensation, cooling ability and so on, the floor radiant system usually combines with down blast system. This system has the important academic prospect and application value in the field of building energy conservation due to its advantages of temperature and humidity independent control and effectively reducing the energy and environmental control

consumption ${ }^{[1]}$. Unlike conventional air conditioning system mainly eliminates indoor waste heat and humidity by the way of air convection heat transfer, but the floor radiant cooling combined with displacement ventilation down blast air supply system transfer heat by thermal radiation and heat convection coupling effect: displacement ventilation system parameters determine the indoor velocity field and humidity field, and coupling with the inner wall temperature parameters (mainly affected by parameters of the floor radiant system), they jointly affect indoor temperature field. Radiation ceiling + displacement ventilation system will decouple temperature and humidity, and displacement ventilation system undertake latent heat load and part of the sensible heat load, while radiation end undertake the rest of the sensible heat load.

In the single floor or ceiling radiant cooling system the air temperature drop mainly through the natural convection heat transfer with the structure and cannot eliminate indoor humidity, when there is more humidity load or when people stay indoors for a long time, will feel stuffy; When the water temperature is lower or the indoor humidity is higher, and the floor/roof surface temperature is lower than the cold air dew point temperature near the radiating surface, radiant panel surface prone to dewing phenomenon. therefore, the introduction of displacement ventilation system is necessary, and its function mainly reflects in the following aspects: 1) the introduction of fresh air, meet the requirements of indoor health; 2) radiant cooling system cannot eliminate indoor humidity, down blast can remove more than indoor humidity; 3) the air supply system can also bear part of the 
sensible heat load, to make up for the defect of the insufficient cooling capacity of single floor radiant cooling system.

But there is also differences between the two systems because of the different radiating surface position in the floor/roof radiation system: 1) in the floor radiation system, the introduction of the down blast can form air layer in the floor surface, a lower dew point temperature of drying air will floor covering, avoid direct contact with the air humidity and low temperature floor, consequently prevent dewing phenomenon; 2) in the floor radiant system, down blast system supply into the attached with air flow can improve the indoor air and the floor surface convective heat transfer, the data show that the system of ground and indoor air convective heat transfer coefficient is about $45 \%$ higher than when used alone floor cooling, 30\% higher than the total heat transfer; 3) In the ceiling radiation system, the convection effect of displacement ventilation on radiant panel is small, the heat transfer of radiant panel relies mainly on the radiation effect, the radiant panel cooling capacity per unit area is lesser, can't enhance convection produced by fresh air ${ }^{[2]}$.

Current research on temperature field of radiant cooling system is more, but the research of humidity field for the system is inadequate. The indoor temperature field is relatively uniform and the vertical temperature gradient is small. While adopting the floor radiant cooling system, the indoor vertical temperature stratification is more obvious. The main reason is that the two kinds of system cooling radiant interior are in the different position. Radiating surface of floor radiant cooling compound system is located in the lower part of the room, and displacement ventilation system is also located in the lower part of the room. The combination of both systems increased indoor vertical temperature gradient; while use of ceiling radiant cooling compound system, the radiating surface is located in the upper room, and displacement ventilation is located in the lower part of the room. The combined work decreased the indoor vertical temperature gradient ${ }^{[3]}$. Since the temperature fields of two radiation systems have such characteristics, are there the similar features in humidity field as that in temperature field? And humidity environment has a great influence on cooling capacity and condensation problem of the radiant cooling system, so it is necessary to study the humidity environment of the two conditions. the thermal and humidity fields in the room that uses floor radiant cooling or ceiling radiant cooling system under different indoor moisture load conditions by the way of CFD simulation is analyzed and compared in this paper.

\section{Methodologies}

The model, which was built according to actual size of the present experiment testing room, will be tested and verified the reliability of simulation results, and then simulated indoor humidity field distribution under different moisture load conditions. Indoor heat load is only from personnel, no other source of heat. The size of test room is $5 \mathrm{~m} \times 3 \mathrm{~m} \times 2.7 \mathrm{~m}$, and air supply outlet is located in the lower part of west wall, $0.2 \mathrm{~m}$ high. The two people that the moisture load for each is $109 \mathrm{~g} / \mathrm{h}^{[4]}$ in the room is the source of moisture. There is no electric equipment such as computer but lamps in the room, to simplify model to facilitate analysis, the heat dissipation of lamps and lanterns is ignored. Fig.1 shows the room model. Using records in the process of experiment parameters as initial conditions, the room air temperature is $22.6{ }^{\circ} \mathrm{C}$, and relative humidity is $50.3 \%$, and cold floor radiant surface temperature is $20.5^{\circ} \mathrm{C}$. In this model, temperatures of envelope and cold radiating surfaces are considered constants, and it is assumed that the surface temperatures are uniform.

The floor radiation model and the ceiling radiation model are established in this simulation, and only one of two systems will be run in the simulation process in the same time. The conditions of table 1 will be simulated. 


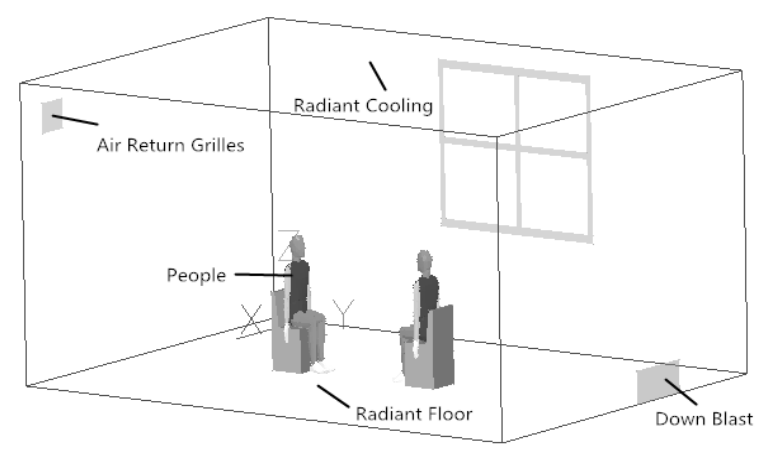

Fig.1. Room Model

Table 1 The setting of each condition.

\begin{tabular}{llll}
\hline & condition1 & condition2 & condition3 \\
\hline Radiating surface temperature $\mathrm{Ts} /\left({ }^{\circ} \mathrm{C}\right)$ & 20 & 20 & 20 \\
Air supply volume $\mathrm{q} /(\mathrm{m} 3 / \mathrm{h})$ & 60 & 60 & 60 \\
Supply air relative humidity $\mu /(\%)$ & 50 & 50 & 50 \\
Supply air temperature $\mathrm{t}_{\mathrm{s}} \mathrm{min} /\left({ }^{\circ} \mathrm{C}\right)$ & 22 & 22 & 22 \\
Indoor humidity load $\mathrm{W} /(\mathrm{g} / \mathrm{h})$ & 218 & 436 & 654 \\
\hline
\end{tabular}

\section{RESULTS AND DISCUSSION}

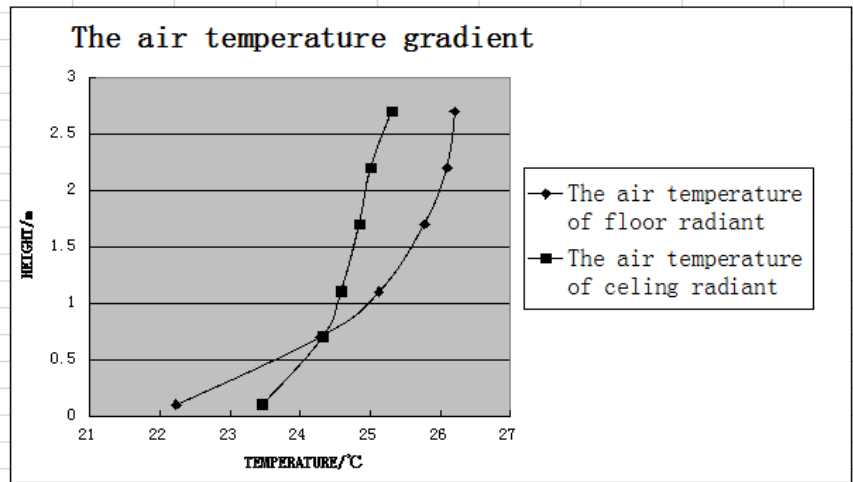

Fig.2 Indoor Air Temperature Gradients under two kinds of Radiant Cooling Systems based on Displacement Ventilation

As can be seen from the Fig. 2, along the height direction, within $0.1 \mathrm{~m}$ to $1.1 \mathrm{~m}$, the vertical temperature difference of floor radiant cooling is $2.89^{\circ} \mathrm{C}$, while the ceiling radiant cooling temperature difference is $1.13{ }^{\circ} \mathrm{C}$. Both are smaller than the ISO7730 thermal comfort standard requires $3{ }^{\circ} \mathrm{C}$ and it satisfies the requirement of the human body comfort; But ceiling radiant cooling temperature difference is smaller, hot comfortableness is better. There are temperature stratifications in temperature field of both systems, and the lower area temperature change is huge, while the upper area of the temperature field is relatively stable.

Supply air relative humidity of 50\%, for example, Fig. 3 (a) shows that due to the cold air that temperature is $22{ }^{\circ} \mathrm{C}$ and relative humidity is $50 \%$ just out of the air supply outlet, the dry fresh air density is greater than the density of indoor air, and under the gravity the cold air sank to the ground and spread to the whole room lake formed air lake. Due to the human body is the heat and humidity source, the cold air around the human body is heated up, and constantly entrains ambient air flow to the top. The stratification is at the height of about $1.3 \mathrm{~m}$ to $1.5 \mathrm{~m}$, and the lower area is clean and air cooler. The sitting people are in the regions of good air quality. 


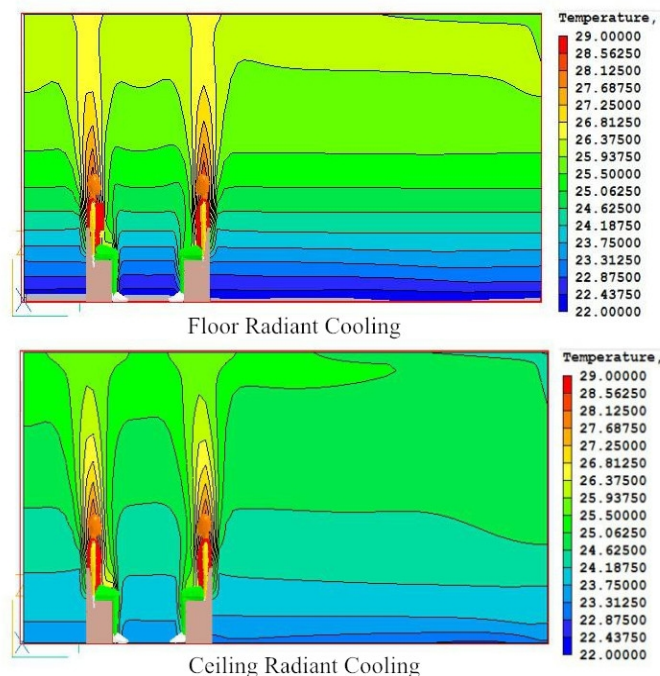

(a)

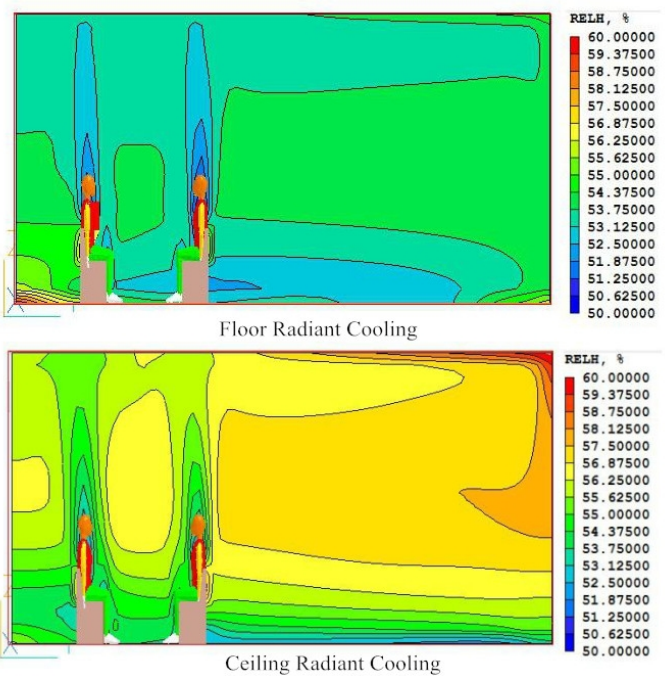

(b)

Fig. 3 .The Temperature Cloud Picture and the Relative Humidity ( $\mathrm{X}=0.7 \mathrm{~m}$, Condition 1$)$

Fig. 3 shows that in the relative humidity field there is a stratified phenomenon similar to that of the temperature field. The relative humidity of the fresh and dry air that just sent out remains at about $50 \%$ and does not change, but as the attenuation of velocity and spread to the surrounding region, humidity increases gradually. Indoor relative humidity and moisture content presented the same stratification as in temperature field.

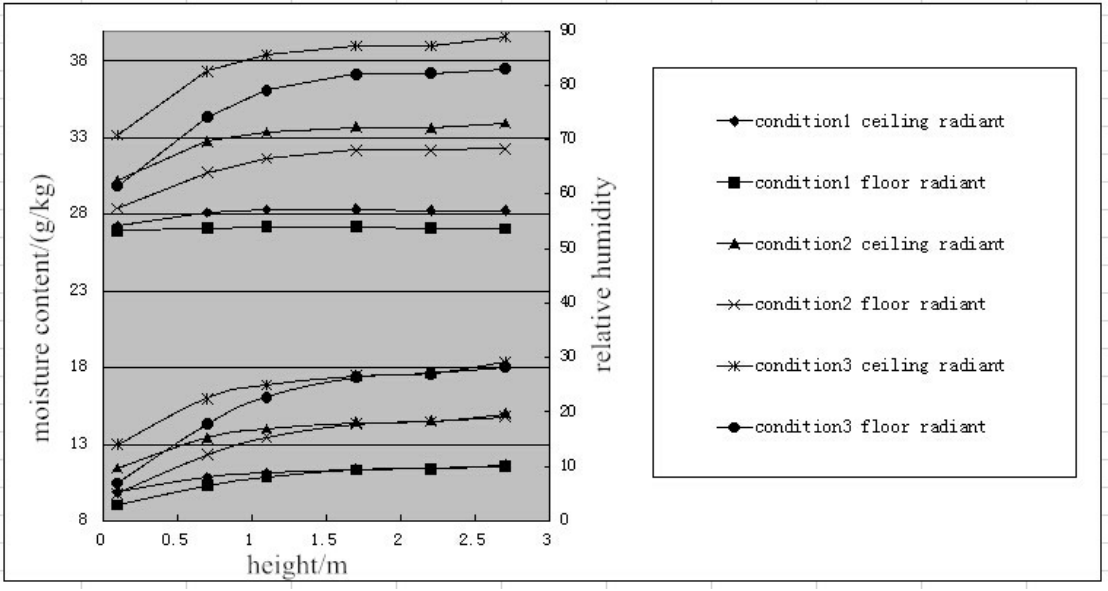

Fig.4.The moisture content and the relative humidity of two radiant forms at different height under 3 conditions $(\mathrm{X}=1 \mathrm{~m}, \mathrm{Y}=2 \mathrm{M})$

Curves in the Fig. 4 also demonstrate in the two kinds of radiation form, the indoor relative humidity increasing begin from the ground and the humidity stratification appears about at $1.3 \mathrm{~m}$ to $1.5 \mathrm{~m}$. the relative humidity of the upper area tends to uniform distribution, the same as the humidity distribution characteristics of hybrid ventilation, while in the lower area the stratification is obvious, and the stratification phenomenon in floor radiant with displacement ventilation conditions is more obvious than another.

In the radiant air condition system, dew point temperature of the radiation surface is the parameter that directly reflects whether appear condensation. Therefore, the dew point temperature at $0.1 \mathrm{~m}$ apart from the radiating surface in the two systems is compared and analyzed in this article.

The room size is $5 \mathrm{~m} \times 3 \mathrm{~m} \times 2.7 \mathrm{~m}$. Selecting 15 points in the $\mathrm{XY}$ plane, dew point temperature calculation formula is ${ }^{[5]}$

$$
\mathrm{t}_{\mathrm{d}}=-35.28896-2.03222 \ln \mathrm{p}_{\mathrm{q}}+1.17025\left(\ln \mathrm{p}_{\mathrm{q}}\right)^{2}
$$


Where $T d$ is dew point temperature of calculation area, $P q$ is the steam partial pressure of wet air in this condition.

$$
\mathrm{P}_{\mathrm{q}}=\mu \mathrm{P}_{\mathrm{q}, \mathrm{b}}
$$

Where $\mu$ is vapour pressure of saturated air of the temperature. Measured and calculated data distribution as shown in Fig. 5.

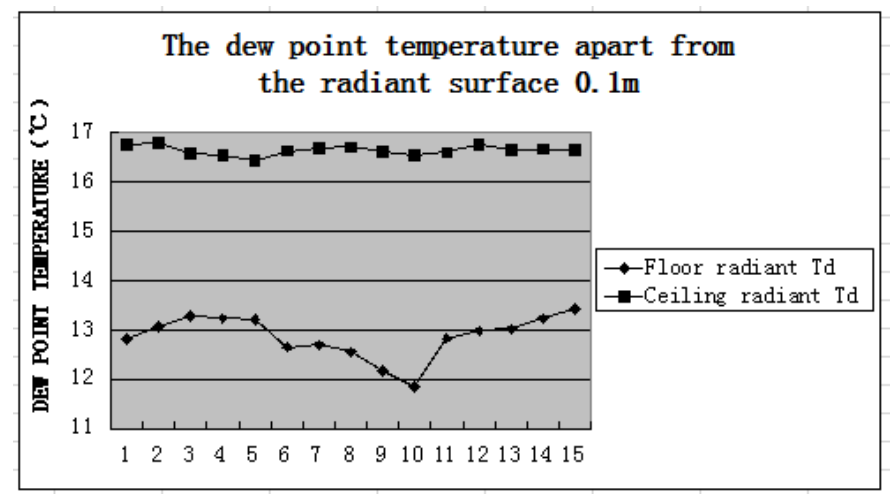

Fig.5.The dew point temperature of $0.1 \mathrm{~m}$ apart from the radiant surface

As Fig. 5 shows, due to the existence of the indoor moisture load, the indoor moisture content and dew point temperature increase. When the relative humidity of supply air is $50 \%$ and other parameters are the same, the dew point temperature that apart from the floor radiating surface $0.1 \mathrm{~m}$ place is lower than that of ceiling radiant cooling about $4{ }^{\circ} \mathrm{C}$. And the air supply outlet is ground installation in this paper. Fig. 5 also shows some point dew point temperature is lower, for the air is not mixed with the air near the floor. It shows that in these working conditions, the anti-condensation ability of floor radiant cooling is better than that of the radiation in the roof. It means in radiant floor system, radiation temperature can be lower, cooling capacity can be higher. The conclusion is that the anti-condensation capacity of floor radiant system is superior to ceiling radiant cooling system under the working condition while the relative humidity of supply air is $50 \%$ in this paper.

\section{Conclusions}

Displacement ventilation systems undertake all the indoor moisture load and part of sensible heat load, and realize the temperature and humidity independent control of air conditioning system. According to the results of experiment and numerical simulation, there is no dewing phenomenon on the radiating surface as long as the design of the system running parameters is reasonable; The analysis results indicate that in displacement ventilation combined with the radiation of the two forms systems, there is the humidity stratification phenomenon. Under the same moisture load conditions, the stratification phenomenon in floor radiation conditions is more obvious. In the upper turbulent flow zone, the moisture content of both is roughly identical, but in the lower part of the work area, the moisture content of floor radiant form is lower than that of roof radiation; With the increase of moisture load, humidity stratification phenomena are becoming ever more obvious. But each stratification height in these cases is roughly identical, and the humidity stratification and thermal stratification are about the same height; While introducing displacement ventilation system, a layer of air lake which is relatively dry and has higher dew point temperature, can be formed in floor surface, and it can prevent the hot air direct contact with the low-temperature floor. In ceiling radiation conditions, due to the cold air in the air lake heated by the heat source formed plume rising, at the same time also to carry away the indoor moisture load generated by moisture source, causing moisture content near the ceiling significantly greater than that near the floor; While the moisture load is not so high and the indoor temperature gradient is strict, the ceiling radiant cooling system based on displacement ventilation can be chosen. While the moisture load is large, the anti-condensation capacity of floor radiant cooling with displacement ventilation system is greater than that of the 
former. As a result, the choice between the two systems should depend on specific engineering requirements.

\section{References}

[1] ZHANG Dongliang, LIU Minghui, RUI Yingxiang. Comparative Experimental Study on Performance of Down Blast and Cooling Systems Combining Dry and Wet Floor Radiation Practices. BUILDING SCIENCE, 12, 55-59.(in Chinese)

[2] Tang Kai, Zhang Xu, Zhou Xiang and Liu Chang. Experiment on operating performance of radiant ceiling and displacement ventilation system in summer. $H V \& A C, 8,94-99$. (in Chinese)

[3] XUAN Yong-mei, HUANG Xiang, KANG Ning. Simulation Study on Indoor Thermal Environment of Radiant Cooling System Based on Evaporative Cooling. FLUID MACHINERY, Changsha, Hunan, China, October 2012, vol. 40, pp. 80-83.(in Chinese)

[4] Liu Shuanqiangn, Liu Xiaohua and Jiang Yi. Dedicated outdoor air system in the THIC air-conditioning system (1): calculation of space moisture load. $H V \& A C, 1,80-84$. (in Chinese)

[5] BU Wen-feng, WANG Shi-hong. Correction of an Empirical Calculation Formula of Dew Point Temperature. JOURNAL OF BEIJING POLYTECHNIC UNIVERSITY, 9, 369-370. (in Chinese) 